\title{
Varying Power Configurations and the Accountability of Independent Regulatory Agencies
}

Fulya Apaydin and Jacint Jordana

\section{OpenEdition}

1 Journals

Electronic version

URL: https://journals.openedition.org/irpp/1458

DOI: 10.4000/irpp.1458

ISSN: 2706-6274

Publisher

International Public Policy Association

\section{Printed version}

Date of publication: 15 December 2020

Number of pages: $342-357$

ISSN: 2679-3873

\section{Electronic reference}

Fulya Apaydin and Jacint Jordana, "Varying Power Configurations and the Accountability of Independent Regulatory Agencies", International Review of Public Policy [Online], 2:3 | 2020, Online since 15 December 2020, connection on 07 September 2021. URL: http://journals.openedition.org/irpp/ 1458 ; DOI: https://doi.org/10.4000/irpp.1458

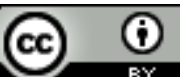

International Review of Public Policy is licensed under a Creative Commons Attribution 4.0 International. 


\section{Varying Power Configurations and the Accountability of Independent Regulatory Agencies}

\section{Fulya Apaydin}

Institut Barcelona Estudis Internacionals, Spain.

\section{Jacint Jordana}

Universitat Pompeu Fabra, Spain; and Institut Barcelona d'Estudis Internacionals, Spain.

\section{Abstract}

Independent regulatory agencies (IRAs) have a significant capability to choose how to implement their decisions to be effective, given the mix of managerial autonomy, supervisory powers and political independence that most of these agencies enjoy. As such, traditional approaches which focus on their institutional characteristics or their reputational problems do not fully capture the variation in IRAs' behavior. This paper suggests a complementary approach to interpreting IRAs' autonomous behavior, focusing on the possibilities that the practice of accountability offers to these public agencies to make relevant choices for the agency itself and the policy environment. To that end, we identify a key background variable that affects the practice of IRAs, namely, the varying power configurations existing among the regulatees and focus on how this factor shapes their voluntary accountability in different contexts. Lastly, we examine several cases of IRA accountability behavior to discuss whether the patterns we submit might constitute a starting point for a theoretical development on the use of accountability by IRAs.

\section{Keywords}

regulation, independence, voluntary accountability, regulatory governance, delegation, asymmetries of power 


\section{Introduction}

Independent regulatory agencies (IRAs) have spread around the world in recent decades, reflecting a broader trend where the contemporary administrative apparatus increasingly accommodates technocratic expertise and unelected officials who are not-directly or indirectly-accountable to the electorate (Vibert 2007). A large amount of research seeks to explain their emergence, diffusion, institutional variations, performance, and many other aspects of them (Gilardi 2008, Jordana et al. 2018). However, studying the behavior of regulatory agencies requires further attention since IRAs are quite unique, given the mix of managerial autonomy, supervisory powers and political independence that most of them enjoy.

To this end, this paper offers a new perspective for the study of IRAs' behavior, providing a conceptual framework to make sense of variations in the implementation of agencies' accountability due to existing power asymmetries among regulatees and agencies' risks perceptions of their accountability choices. The suggested conceptual framework allows us to propose a typology of accountability outcomes based on these two dimensions when they activate accountability tools beyond legal requirements. The different accountability outcomes we identify are illustrated with five episodes of agency behavior, showing the value-added of the proposed typology to better explain agency choices in dealing with accountability. In our theoretical discussion, we also take into account that agencies' behavior combines two different goals: reputation-building, which aims at long-term agency survival, and mandate achievement, whereby agencies seek to perform short- and mid-term regulatory objectives. Accordingly, we suggest that accountability choices may be influenced by how these goals are prioritized by IRAs' leadership.

To date, existing works have focused on unpacking the accountability of IRAs (Baldwin et.al. 2012, Black 2008, Biela and Papadopoulos 2014, Fernandez-i-Marin et al. 2015, Koop 2011, 2014, May 2007, Magetti 2010, Scott 2000) by looking at the direction of relationship between IRAs and their stakeholders, or identifying the variables affecting their strength. Going beyond these studies, we detail a framework for analysis that zooms on IRAs' capability to decide on the use of accountability mechanisms, considering the varying power configurations among agency regulatees -the most relevant stakeholders for IRAs. Power asymmetries exist in all regulated sectors: big firms vs. emerging ones, well-organized groups of consumers vs. unorganized ones, concentrated vs. fragmented producers, to name a few. In this study, we broadly identify regulatees as those actors directly or indirectly affected by the regulatory decisions of the agency, including producers, sellers, consumers and final users, and their collective action initiatives. Within this framework, we lay the groundwork for an analysis of agencies' behavior, highlighting the importance of decisions on expanding or restraining the use of accountability related to their discretionary decision-making processes as a relevant tool to make them more effective.

The debate over IRAs' accountability mechanisms emerged in response to concerns over the disruption of classical accountability relationship towards the executive in democratic regimes following the expansion of these agencies (Biela 2014, Black 2008, Maggeti 2010, Jordana et al. 2015). Scholars suggest that IRAs need to establish credible accountability mechanisms to be able to pursue agency goals, either to protect themselves against political intervention (Koop 2014), sustain a positive reputation (Busuioc and Lodge 2015), or advance their regulatory mandate (Eriksen 2020). Agencies engage in accountability practices because this is mandatory for them as part of the formally established laws and regulations, but they can also expand their accountability by means of voluntary practices, which may be internally formalized 
or fully informal. In this sense, IRAs are faced with the choice to develop and expand voluntary forms of accountability under very different circumstances.

Voluntary accountability refers to agencies' commitment to provide information and explanations about their actions to other actors, without any legal requirement. According to Koop, voluntary accountability is "the degree to which an actor is, without being required to, committed to offering information on, and explanation of, his or her own conduct to another actor, and may be sanctioned for this conduct" (Koop 2014, p.565). Existing empirical research has largely concurred that accountability practices of IRAs often go beyond established requirements (Baldwin et.al. 2012; Schillemans 2008; Verhoest et al. 2010; Koop 2014, Verschuere et al. 2006). There are regular patterns of agency commitment to accountability practices that are not required by law (Busuioc 2013; Busuioc and Lodge 2015; Koop 2014; Puppis et.al. 2014; Schillemans 2011). These can include shared but usually unwritten norms that are created, communicated, and enforced outside officially sanctioned channels such as bilateral exchanges with different entities and organizations, open conferences or specialized workshops, issuing of press releases, disclosing minutes and relevant reports, and/or introducing auditing and complaint procedures beyond the formal requirements. At the same time, these exchanges often take place in diverse environments characterized by varying degrees of power asymmetries among the regulatees.

How do these power asymmetries affect the voluntary accountability behavior of the agencies? Under what conditions do IRAs become more sensitive to such power inequalities? In response to these questions, we suggest that the logic followed by independent agencies is driven by two background dynamics that are not immediately observable. First, we expect that IRAs will deliver more voluntary accountability to regulatees, with different modalities, when power asymmetries existing among them are higher. Second, we argue that this may also be shaped by the risks related to the use of voluntary accountability, as perceived by the agency itself. The agency behavior may change depending on their assessment of risks, considering also how these uncertainties may have an impact on the agency goals they value most. This is because the agency aims to defend its decisions, to advance its mandate, but also to strengthen its existential purpose, and safeguard its reputation.

In the remaining sections, we develop an interpretative framework to make sense of voluntary accountability practices by IRAs, suggesting that these are employed to cope with the difficulties that inequalities among regulatees create to implement their regulatory decisions. The next section presents the conceptual agenda in more detail. We discuss the formation of IRAs' preferences to perform voluntary accountability outside their formal institutional design. This helps us to better assess agency choices on their accountability front and observe under which circumstances they seek to strengthen (or weaken) voluntary accountability mechanisms. The following section unpacks power configurations as a background condition affecting IRAs' strategies to modulate their accountability practices. Thereafter, we provide five examples detailing accountability practices under different power configurations and show how our conceptual framework on the voluntary accountability of agencies can be applied to better understand agencies' behavior. Finally, we conclude with some remarks on the implications of analyzing accountability as a component of IRAs' strategic actions.

\section{Accountability of IRAs: why is it important?}

Within the realm of traditional public administration, civil servants remain accountable to elected politicians by means of hierarchical subordination (Bovens et al. 2014, Przeworski et 
al. 1999). However, administrative innovations in the past few decades have weakened this relationship, creating "transactional authority" based exchanges, which rest on the premise of "bargaining and mutual exchange that reflects a partnership-albeit sometimes a contested one-between the principal and its agent" (Carpenter and Krause 2015, 8). This approach abandons the premise of a dominant hierarchical relation, as is expected for agents within the Weberian administrative state, and suggests that public agencies may have a certain degree of bureaucratic autonomy. However, while many public agencies are increasingly involved in such complex relations, they still remain accountable to the authorized executive unit that controls the agency.

To the extent that most public agencies are politically accountable to elected officials, they establish a relationship in which they exchange information, and have a duty to justify and to defend their behavior, eventually facing consequences or rewards (Bovens 2007). These accountability exchanges promote arrangements that curb the actors' capacity to deviate from politicians' policy priorities, even in the absence of a strong hierarchical subordination. This also has an impact on reinforcing agencies' accountability towards their stakeholders. As pointed out by Schillemans (2008), such accountability relationships are effective because they run in the shadow of hierarchy. In other words, the existence of accountability mechanisms for agencies within the political sphere is what establishes a credible threat for the agency, albeit an indirect one. Schillemans argues that inadequate accountability with stakeholders may reactivate the "political" accountability relationship and trigger serious consequences for agencies. Thus, it can be argued that agencies cultivate accountability with stakeholders as a way to prevent or neutralize potential impacts derived from such "political" feedback effects, and stakeholders are also aware of such potential impacts that reveal the "vulnerability" of agencies. This dynamic makes their accountability relationship credible.

Contrary to most public agencies, however, IRAs' "political” accountability relationship tends to be very weak, reducing the shadow of hierarchy effect as conceptualized by Schillemans. The formal "political" accountability of IRAs is very limited, often involving only regular, pro-forma presentations of reports and hearings to the legislature (Koop and Hanretty 2018, Verschuere et al. 2006). In fact, these bodies exhibit distinct institutional characteristics within the public realm, including protections against political interferences in their regulatory operations (Gilardi and Maggetti 2011, Hanretty \& Koop 2012, Jordana et al. 2018). Therefore, IRAs are conspicuously different from most public agencies on the accountability front, and consequently, their accountability relationship operates on a different logic.

Under these circumstances, if accountability to the executive is feeble or even discontinued, and accountability to the legislative is limited, the complex association between "political" accountability and stakeholders' accountability expectations becomes quite difficult to balance. Thus, the shadow of hierarchy effect may be hardly operational - except for critical situations, for example when the termination of the agency is at the stake. Without this effect, regulatees should be unwilling to engage in an accountability relationship with IRAs since they would not be able to trigger "political" accountability when tensions emerge. Consequently, if regulatees do not perceive agencies' "vulnerability", they might search for alternative channels beyond IRAs to have a voice in the policy process. However, there is ample evidence that regulatees are strongly involved in accountability relations with IRAs (Fernandez-i-Marin et al. 2015), even beyond those legally defined (Koop 2014, Koop and Hanretty 2018). The question then becomes: under what circumstances do IRAs develop credible accountability vis-à-vis the regulatees in the absence of a shadow of hierarchy, and what are the consequences they face as a result of this? 
We argue that, to compensate the absence of the shadow of hierarchy effect, IRAs have to show some credible "vulnerability" when providing accountability to their regulatees. The practice of voluntary accountability in many cases serves this purpose. Busuioc and Lodge (2015) indicate that accountability responses of public agencies — in general-are primarily driven by reputation-related concerns, and "vulnerability" may involve, under certain conditions, putting their reputation at risk. However, we suggest in this paper that IRAs also employ accountability mechanisms for other purposes as well, not only to improve their reputation but to advance strategically the mandates they have (Eriksen 2020). Thus, in a context of weak or almost nonexisting shadow of hierarchy effect, when IRAs voluntarily account for their decisions, they may introduce some "vulnerability" in their decision-making process. In compensation, they will expect regulatees to be seriously involved in the implementation of agencies' decisions. Under these circumstances, voluntary accountability of IRAs would further involve a strategic component to selectively influence regulatees' behavior towards agencies.

For IRAs, developing a strategic capacity for managing voluntary accountability allows them to avoid potential threats to their regulatory decisions. Such accountability practices are aimed to shape regulatees' attitudes and preferences by means of detailed information, discussions and deliberations, while revealing the agencies' "vulnerabilities" to them. Consequently, our approach also focuses closely on the importance of identifying the accountability preferences of IRAs. Thus, agencies may commit to voluntary accountability, decide on how selective they should use it, and which instruments fit better to their context and capabilities. Options refer also to the introduction of accountability interfaces, allowing regulatees' feedback on the instruments and policies adopted by the agency. Indeed, IRAs' preferences on voluntary accountability should consider different options regarding how to frame regulatory problems, and how to justify the actions implemented by the agency, under the constraints placed by power configurations existing among regulatees. After detailing the concept of voluntary accountability in the next section, we propose an interpretative framework to analyze how agency preferences on voluntary accountability are influenced by regulatees' power asymmetries.

\section{Understanding IRAs' voluntary accountability: a focus on the context}

IRAs have several important duties. On the one side, law-makers delegate statutory responsibilities to them, including, but not limited to, information gathering, rulemaking, monitoring and control, enforcement, adjudication, and the implementation of rewards and sanctions over issues of market governance and other areas of public concern, such as risk regulation (Puppis et al. 2014). On the other side, most statutes of these agencies include legal provisions that guarantee independence from political intervention. This means their internal decision-making processes are subject to special protections and the decisions they make cannot be arbitrarily reversed. While public agency officials in managerial positions in traditional bureaucracies could be removed or replaced more easily, IRA board members have fixed-term mandates and cannot be removed from their post unless they violate specific terms of their appointment and/or commit a serious offense (Scott 2000).

To be sure, IRA independence is a multidimensional concept that goes beyond statutory independence and formal legal status, although there is not a clear consensus on how to measure and conceptualize it (Gilardi and Maggetti 2011). At the most basic level, this includes three key components: political independence, managerial autonomy, and regulatory responsibilities (Jordana et al. 2018). Depending on the combination of these elements, agency independence may vary, leading to diverse outcomes regarding the actual exercise of autonomy (Verhoest et al. 2004, Christensen and Laegreid 2006), and defining several institutional configurations, 
ranging from fully independent entities to a variety of non- independent but autonomous agencies (Jordana et al. 2018).

To the extent that they are independent, IRAs show different conventions than traditional public agencies for the management of accountability practices. However, higher independence does not mean greater accountability for all agencies. From a recent dataset on the formal characteristics of regulatory agencies world-wide, Figure 1 clearly illustrates a positive relationship between the formal requirements of accountability to stakeholders and the legal protections for agency independence, although not a very intense one: the dots, referring to country means of agencies, show the existing dispersion between these two dimensions. ${ }^{1}$ On the other side, if we only look at formal "political" accountability, it tends to be positively associated with low levels of agencies' formal independence (Koop and Hanretty 2018).

Figure 1. The accountability and independence map of IRAs worldwide

Figure 1. The accountability and independence map of IRAs worldwide

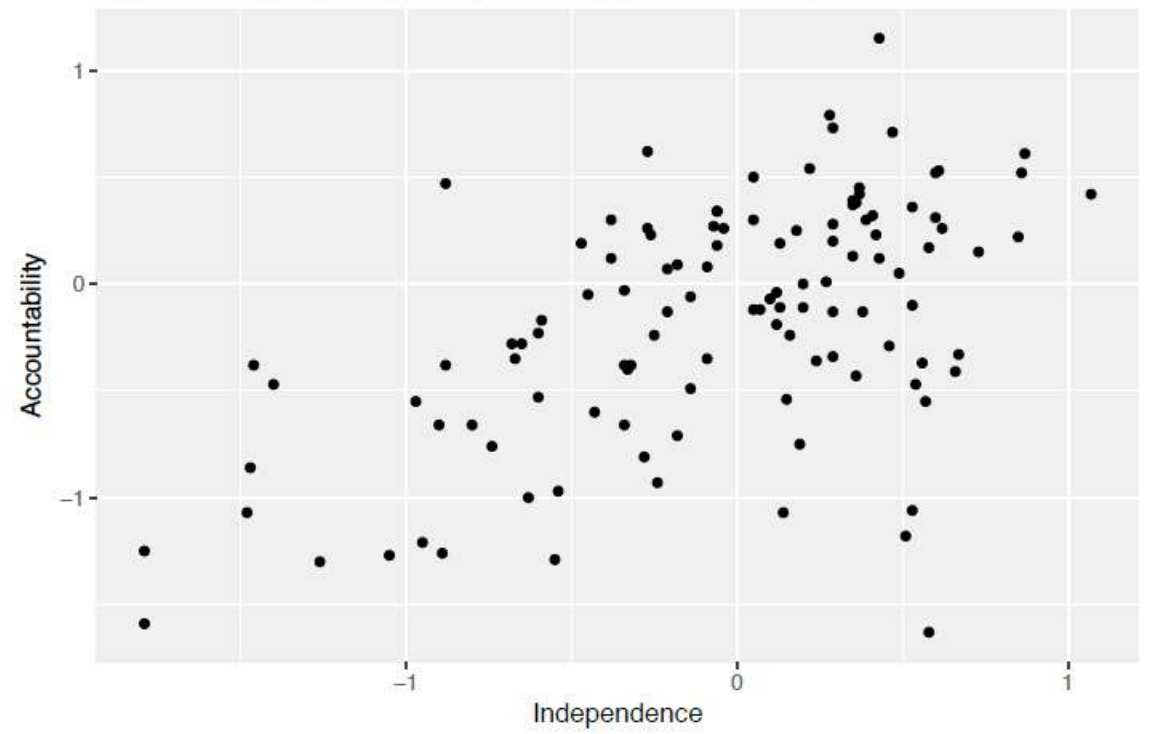

Note: The data includes normalized accountability and independence scores for 115 countries. Data source: Author's own.

Under these circumstances, it is not surprising that the use of voluntary accountability (or even the intensification of already existing formal mechanisms) could be used by IRAs to adjust their desired accountability levels in response to a particular situation, going beyond formal requirements. Independent agencies may use voluntary accountability under different circumstances, and this leads to a variation across agency practices. We should not expect a positive as-

1 - This finding is based on a dataset of legal characteristics of IRAs that reveals four main latent dimensions for the analysis of IRAs: managerial autonomy, political independence, public accountability and regulatory responsibilities (Jordana at al. 2018). The correlation coefficient between the independence and the accountability dimension is relatively low: only 0.348 for the whole dataset, and 0.404 if we include only agencies from OECD countries. Each latent dimension is constructed by means of a factor analysis that includes several variables about the formal characteristics of agencies related to them and, in particular, the accountability dimension measures largely non-hierarchical mechanisms. 
sociation between the practice of accountability and agency performance either (as confirmed by Koop and Hanretty 2018), because accountability is not accumulative to the achievement of agency goals. Diminishing returns of accountability may indeed be the outcome in some cases of intense use, and we might even observe cases in which accountability mechanisms could be invoked by some regulatees to undermine agencies' decision-making procedures.

The independence enjoyed by regulatory agencies involves some flexibility as to how to use accountability tools, including the introduction of voluntary accountability, and this has consequences on the strategic front. IRAs' capabilities to make a calculated use of accountability, and to expand its content beyond legal requirements, are contingent on its independence, which allows them to use it as an instrument for strategic purposes. Significant levels of independence would be necessary to make choices on their own on this front, but agencies with moderate levels of independence may be also capable of using voluntary accountability to advance their purposes. If an independent agency decides to reveal its decision-making procedures (for example, by revealing the entire document trail), in most cases there are no formal limitations that would prevent it from doing so. Similarly, if an IRA decides to strictly bound itself to the mandatory accountability requirements, it is also technically free to do so. In that sense, we claim that the agency behavior on the accountability front is strongly informed by the flexibility it enjoys thanks to its independence.

\section{Varying power configurations}

We argue that variation in the practice of voluntary accountability by IRAs is influenced by varying power configurations among regulatees, in addition to agency preferences regarding the level of risk that its decisions entail. The combination of these dynamics allows us to identify four different options, as detailed in Table 2.

In regulatory policy, highly motivated large companies face the many and usually less informed small firms operating in the same markets (Dal Bo 2006, 220). Power asymmetries among them are observed when the former can easily cover costly litigation processes, obtain access to the legislature through multiple lobbying procedures, or even influence public servants via effective media pressure, while the latter do not have such capabilities or their costs are much higher. In addition, the performance of IRAs depends on business' regulatory compliance, and most often this requires a positive involvement of firms already dominating the markets or policy areas under regulation, while new entrants, eventually bringing innovations to the sector, are in a much weaker position in this respect.

In addition to firms, there are other regulatees - such as end users and consumers-who are indirectly influenced by the regulatory decisions. This group includes many individuals that are often poorly informed and less organized to compensate power asymmetries vis-à-vis large producers and service providers.

This diversity among the regulatees to process information, demand explanations and exert direct or indirect pressure suggest that asymmetric power configurations are quite important in the regulatory process. After all, not all regulatees are equally powerful and-in certain issue areas-some matter more than others (Busuioc and Lodge 2015, Carpenter and Krause 2012). In that sense, some actors may face major difficulties to push the agency to be more accountable when contradictory views and diverse interests prevail (Bovens 2007). Under these circumstances, the existence of collective action problems may prevent some actors from being active in participatory platforms (Biela and Papadopoulos 2014, 7, Guidi 2015, 117), and even generate additional costs in case of openly criticizing the agency. When this is the case, IRAs 
are not only passive recipients of their regulatees' demands but they also may employ voluntary accountability more strategically as a way to reinforce their decision-making power.

Inspired by Wilson's definition of regulatory policy (1980), we schematically detail different power configurations among regulatees and suggest that these can be divided in two groups: producers and sellers, who are supply-driven, vs. consumers and final users, who are demanddriven. Clearly, this involves some simplification, but it is heuristically necessary to advance a conceptual framework on IRAs' voluntary accountability. Except for very large firms with near-monopoly power, most regulatees face collective action dilemmas to cope with asymmetric power configurations in their domain. Each policy area and issue leads to a different power configuration among regulates. This may be due to the market structure, the position of the firms and their structural power within this environment. In that sense, consumers and users may have insufficient capacity for collective action, while producers and suppliers may face collective action problems due to their internal competition ${ }^{2}$. This leads to distinct power configurations, ranging from low to strong asymmetries among regulatees (Table 1).

Table 1: A map of power configurations involving regulatees and market structure

\begin{tabular}{|l|l|l|}
\hline \multicolumn{2}{|l|}{ Regulatees } & Unorganized \\
\hline Market structure & Organized & Strong asymmetric configuration \\
\hline Concentrated & $\begin{array}{l}\text { Moderate asymmetric } \\
\text { configuration }\end{array}$ & Moderate asymmetric configuration \\
\hline Dispersed & Low asymmetric configurations
\end{tabular}

Source: The Authors

As Table 1 reveals, when regulatees are organized, capable of resolving collective action problems and mobilizing resources, asymmetries in power configuration still exist because of the market structure, but tend to be moderated or low. Under these circumstances, IRAs can rely on more efficient tactics, playing firms off against one another to release information on costs, balance sheet specifics and drastically lowering existing power asymmetries between companies and their beneficiaries. For example, if consumer groups or small firms lack access to information on the real costs and production strategies employed by large firms, agencies may like to challenge these companies to release some of this information. However, if the consumers or emerging firms are unorganized, while large companies dominate the market structure, this leads to the prevalence of strong power asymmetries. Additionally, when a few large companies do not dominate the market and other regulatees are not sufficiently organized to cope with the regulatory process, the power asymmetry configuration tends to be moderate.

We argue that choices on the voluntary accountability by IRAs are conditioned by the asymmetry of power configurations existing in a regulatory regime. As a tentative proposition, we expect that voluntary accountability mechanisms will be used intensively if power asymmetry is strong. If asymmetry is low, we suggest that the use of accountability will remain at a

2 - The literature on collective action and interests' groups is extremely large and rich, departing from the seminal work of Mancur Olson (1965), and we do not intend to discuss this extensively in this paper, but merely indicate that the collective action of regulatees has to be taken into account when examining their asymmetric power, in addition to more structural conditions shaped by markets and institutions. 
more moderate level. This attempt to link power dynamics into the study of accountability in IRAs also follows Keohane's understanding of accountability as a power relationship (Keohane 2006), but introducing an interactive perspective based on the fact that IRAs have to be open to some "vulnerability" to make their accountability credible to regulatees, while IRAs' accountability actions eventually may have an impact on the power configurations among regulatees. Asymmetries of power within regulatees influence agency incentives in modulating their voluntary accountability, making it less necessary when salience is less pronounced. When asymmetries are high, however, agencies would be more tempted to use their accountability instruments to address challenges to their regulatory decisions, for example by trying to undermine the influence of some regulatees acting as informal veto players.

We suggest that agencies' calculations about voluntary accountability also take potential reactions of regulatees into account. This is not only influenced by their relationship to the agency, but also how the agency views the relations among them. In fact, some accountability decisions may even have a second-order impact on the configuration of power asymmetries. Given the variety of power configurations involving regulatees, IRAs face numerous difficulties to navigate the murky waters of accountability without jeopardizing their relevance, status and reputation, making the challenges they confront highly relevant. For this reason, the practice of voluntary accountability involves some significant risks for IRAs. From this perspective, we consider that agencies' leadership can be risk-averse, or risk prone in their voluntary accountability practices. In the first case, concerns about preserving the agency's stability or reputation may dominate over actively using accountability tools to support its decisions, while in the second case, the agency will be committed to make their decisions effective, and this may result in a more selective use of voluntary accountability.

Table 2: Voluntary Accountability Outcomes

\begin{tabular}{|l|l|l|l|}
\hline \multicolumn{2}{|c|}{} & \multicolumn{2}{|l|}{ Asymmetric Power } \\
\cline { 3 - 4 } \multicolumn{2}{|l}{} & Strong & Moderate \\
\hline \multirow{2}{*}{ Agency preferences } & Risk-averse & Intense and generic & Low and generic \\
\cline { 2 - 4 } & Risk-prone & Intense and selective & Low and selective \\
\hline
\end{tabular}

Source: The Authors

When agency leadership tends to be risk-averse, they prefer to use voluntary accountability in a generic way, meaning that the instruments and the channels to account for agency actions and decisions to regulatees are expected to be of general concern, not focusing on the problems and needs of a particular group of regulatees. We expect that in cases where agencies exhibit greater propensity to take risks, they will be more selective in the use of their voluntary accountability instruments, aiming to influence some of their regulatees in particular - albeit that this will increase their potential vulnerability. In that sense, agencies can activate preferred channels and intensify the contents of voluntary accountability also to empower designated actors involved in the regulatory process. The motivation behind this strategy is to slightly alter the power configurations existing among regulatees, with the expectation that this would help to implement agency decisions more effectively, eliminating opposition and building a support base among the audiences. 


\section{The practice of voluntary accountability by IRAs}

In this section, we focus on the determinants of voluntary accountability identified earlier and, using several examples, discuss how the power asymmetries and risk attitudes highlighted above may influence IRAs' accountability decisions. We present five brief cases of the deliberate use of voluntary accountability by regulatory agencies which range between very intense and very low. In each case, we identify how regulatees' power asymmetries created distinct frames that influenced choices on voluntary accountability made by regulatory agencies and discuss how these power asymmetries tend to increase the intensity of voluntary accountability. We also consider the preferences of the agency (which informs their strategies for the use of voluntary accountability) and whether they are risk-averse or risk prone.

Our first case refers to a very intense use of accountability by IRAs, and the example comes from a study by Puppis et al. (2014), who find that financial, telecommunications and broadcasting regulators in four Western European countries (the United Kingdom, Germany, Ireland, and Switzerland) increasingly focus on informal communication over media platforms to interact with industry representatives and the public (Puppis et al. 2014, 397). This is a sector where mandatory accountability practices are already strong and effective, yet they appeared insufficient to the agency leadership. This is because regulatees interacted in a strong asymmetric power environment: in finance and telecommunications, large firms dominating the market are disproportionately well-informed as opposed to small firms and consumer groups, which lack access to technical details. If IRAs frequently interact with large business groups on the basis of mandatory accountability, which give them a platform to voice their demands and respond to their concerns, they risk losing acceptance in the eyes of broader groups' regulatees. To that end, IRAs in these countries have used public communication to effectively increase voluntary accountability (such as explaining and justifying their actions via mainstream media, trade journals, news agencies, contact with special analysts, and targeted dissemination of information via financial press), to be open to scrutiny by industry representatives and the general public alike (Puppis et.al. 2014, 400). In doing so, they placed great value on the public acceptance of the goals established for the agency, thanks to the broad reach of the new communication tools. Here, we observe that voluntary accountability mechanisms were introduced widely with the purpose of leveling the playing field among stakeholders, but not selectively, keeping risks associated with this strategy quite low.

A second case refers to a situation where voluntary accountability is quite low but selective. The example comes from Australia, where Murray-Darling Basin Authority-an independent regulatory agency responsible for managing water resources-relied on some voluntary accountability measures (e.g. holding public events, producing factual brochures, commissioning scientific reports, providing the latest news on Basin events, organizing natural life preservation awareness weeks that brings interest groups together as well as producing regular updates on drought conditions) in response to a strong backlash from the agricultural industry (including local communities whose livelihood depended on farming and fishing) against its preservationist policies (Wood 2015). In this particular case, selective voluntary accountability served as a "secondary mechanism for resetting the institutional base of the agency to rebuild its political legitimacy, since initial methods (the public consultation) encountered problems" (Wood 2015, 1027). Specifically, we observe that the use of selective voluntary accountability mechanisms emerged when the IRA perceived moderate asymmetry within the regulatees and users (unorganized preservationists on the one side, divided producers on the other), making voluntary accountability manageable and allowing the agency to be risk-oriented to advance 
its goals. Thus, this appears to be the preferred practice to address some perceived problems of regulatory performance that pose a threat to agencies' decision-making.

Case 3 introduces an example of the intense use of voluntary accountability with selective strategies. In particular, we look at the experience of financial regulatory agencies in the US prior to the 2008 subprime mortgage crisis. Critics suggest that asymmetries among regulatees induced by powerful industry players were the primary reason behind the accumulation of market risks, as conventional and shadow banking professionals carefully lured the regulatory agencies into believing that new financial products (such as mortgage-backed securities, credit default swaps and collateralized debt obligations) were safe and did not pose any systemic risk. While mandatory accountability measures of IRAs, including the Securities and Exchange Commission (SEC), appeared strong and solid, these were increasingly ineffective to prevent regulatory bias favoring the industry players, as the information provided lacked the necessary knowledge and expertise regarding the technical details of how these products were structured (Baker 2010). In particular, the skyrocketing profits reported by these actors during the 1990s allowed them to avoid closer inspection as long as profits kept on rising. This further enabled financial industry giants to mobilize and lobby for regulation designed to benefit their business model (Baker 2010, 651).

The case of SEC stands as a clear example of strong power asymmetry, where small investors and consumers were almost absent from these debates. In response to this, the SEC decided to be more proactive and introduced ad-hoc, selective voluntary accountability measures to secure the flow of information across different public bodies by signing a Memorandum of Understanding with Commodity Futures Trading Commission, the FED, and the Department of Labor. However, these mechanisms were vastly useless in the absence of a statutory scheme that formally prevents the formation of a silo-effect from taking place. ${ }^{3}$ In addition, the SEC engaged in several rounds of informal consultation with investors to ensure greater shareholder participation in financial company management and proposed proxy rules. Yet, these measures still favored large companies over ordinary shareholders and retail investors by keeping the required threshold of investment share too high-at \%5- to permit effective exercise of shareholder power, especially in large cap companies (Aguilar 2009). ${ }^{4}$

In that sense, it can be argued that the looming power asymmetry prompted SEC to activate voluntary accountability mechanisms, targeting particular actors as a strategy to influence the existing power and information asymmetries. However, in this particular case, the voluntary accountability strategy was not enough to protect the interests of the consumers and also foster efficient market competition - and the potential risks taken by the SEC were fully revealed when the financial crisis broke out in 2008. Thus, the case of the SEC reveals that selectively expanding voluntary accountability is not always successful and can incur significant costs on the agency, involving higher risks. Accountability mechanisms were insufficient to induce a more effective financial regulation. Overall, this put the agency behavior under focus, and contributed to the general questioning of its independent status for several years afterwards.

\footnotetext{
3 - See "Testimony Concerning the Role of Federal Regulators: Lessons from the Credit Crisis for the Future of Regulation" by Chairman Christopher Cox, U.S. Securities and Exchange Commission, Before the Committee on Oversight and Government Reform, United States House of Representatives, Thursday, October 23, 2008. https://www.sec.gov/ news/testimony/2008/ts102308cc.htm

4 - Speech by SEC Commissioner: "Increasing Accountability and Transparency to Investors", by Commissioner Luis A. Aguilar, U.S. Securities and Exchange Commission, Remarks at "The SEC Speaks in 2009" Washington, D.C., February 6, 2009. Retrieved from: https://www.sec.gov/news/speech/2009/spch020609laa.htm
} 
The last two cases we include here refer to cases of low voluntary accountability practices. Case 4 comes from independent central banks, which operate in an environment where stakeholders are dispersed and disorganized. In one case, a risk-prone attitude in favor of transparency led central banks to use accountability selectively. This occurred when they revealed very detailed information in their market forecasts. After inflation targeting became the key goal of most independent central banks worldwide, having many policy implications, most of these institutions began to publish openly their near-term expectations as a selective piece of information of great interest for some of their audiences. In some cases, however, revealing the process behind the calculation of these figures put the effective targeting at risk, as many reactions anticipated such predictions. This was a risky strategy aimed to increase the efficiency of this central banks' policy instrument, but repeatedly doing so raised further doubts when announced figures were revised within a short time frame, suggesting that central banks' previous policy settings were a mistake and were creating a potential threat to their reputations (Mishkin 2004).

Our final example-Case 5-is about the Federal Communications Commission (FCC) and its response to net-neutrality campaigns in the US, where the agency chose to restrict its voluntary accountability non-selectively because it has considered this could be a risk for the achievement of its regulatory goals, despite the presence of an average power asymmetry regarding the issue under dispute. Since 2014, large internet service providers lobbied to impose price hierarchies in broadband use and called on the FCC to reverse the equal access principle, while well-organized consumers, small businesses and start-ups opposed this proposal. ${ }^{5}$ In response to their demands for greater transparency, however, FCC regulators deliberately toned down their responsiveness to public appeals, remained silent in the face of net-neutrality campaigns and refused to explain the reasons behind their decisions. ${ }^{6}$ To that end, the agency pushed forward to eliminate net-neutrality on June 11, 2018, and enabled broadband providers to impose price hierarchies on Internet use. The FCC defended this controversial decision by framing it in terms of effective governance of the market. Specifically, the chairman of FCC, the Ajit Pai, claimed that "the repeal will get rid of unnecessary and harmful Internet regulations and help spur investment in 5G and other broadband networks." In sum, this represents a case where limited, non-selective voluntary accountability was adopted as choice by the FCC because of its risk averse strategy and the moderate asymmetric power relationship existing among regulatees.

\section{Conclusion}

This paper has introduced a complementary framework to study the accountability of IRAs as a component of their premeditated behavior with a focus on the interaction between independent regulators and their regulatees. Overall, the framework developed in this paper outlines a roadmap to study the voluntary accountability practices of regulatory agencies in further detail, with an emphasis on the strategies that deal with regulatees power asymmetries. Importantly, the use of voluntary accountability by IRAs can be influenced also by agency perceptions about risks related to their strategic options. Under these circumstances, the voluntary

5 - For a recent campaign, see http://www.pewinternet.org/2017/11/29/public-comments-to-the-federal-communications-commission-about-net-neutrality-contain-many-inaccuracies-and-duplicates/, Accessed on October 5th, 2018.

6 - See https://www.engadget.com/2017/12/11/hypocrisy-at-the-fcc-and-the-illusion-of-transparency/, Accessed on October 5th, 2018.

7 - See https://arstechnica.com/tech-policy/2018/05/net-neutrality-to-die-on-june-11-as-ajit-pai-blasts-specialinterests/, Accessed on October 5th, 2018. 
accountability of agencies can be either selective (addressing particular regulatees) or nonselective, where the intensity of voluntary accountability also varies.

As the discussion reveals, the examples we provide substantiate our expectations, underlining the fact that the voluntary accountability behavior of an IRA is related to the power configurations among regulatees. Brief anecdotes reveal a concurrence between the theoretical predictions and the common trends, meaning that strong power asymmetry induces a more active use of voluntary accountability, as the case of telecommunications agencies in Europe reveals (Case 1). In the same way, when an agency perceives that power asymmetry is low and is ready to take some risks, it may opt for a selective use of voluntary accountability to empower some of the regulatees (Case 2). A more dangerous case emerges when power asymmetry is high and the agency is very active on the voluntary accountability front, behaving selectively to address a particular problem (Case 3). Other examples reveal that under conditions of moderate asymmetry, the use of voluntary accountability tends to be limited and conditional on the risk perceptions of the agency (Cases 4 and 5). It must be added that these brief anecdotes are not meant to test any hypothesis, but rather to provide a brief mapping exercise to identify new avenues for testing the role of power asymmetries across a broader sample. In that sense, these are heuristic devices to illustrate the hypothesis-generating potential of the proposed research agenda.

Clearly, more research is required to better understand the impact of asymmetric power configurations among regulatees in relation to IRAs' accountability practices across different sectors and countries. For example, it is important to explore how IRAs cope with environments characterized by strong power asymmetries, especially when a powerful actor uses a combination of negative and/or positive incentives to shape agencies' practices and decisions in line with its own interests (Grabosky 1995a; 1995b). Under these circumstances, IRAs may use voluntary accountability selectively as a strategy to undermine the dominance of such powerful actors. When this is the case, voluntary accountability mechanisms may be targeted to empower specific constituencies, or specific regulatees in particular. However, risks for the agency in case of deciding to activate selective voluntary accountability are high, as they need to open spaces of "vulnerability" so as to be credible and engage the prioritized regulatees, but other actors may exploit this opportunistically. Their costs in terms of reputation and mandate accomplishment can be greatly elevated if such tactics turn out to be contradictory or unsustainable. Agencies may even face the risk that "political" accountability mechanisms could be reactivated, posing a threat of agency termination.

Overall, it emerges that strong power asymmetries play an important role in the choice of voluntary accountability, which may influence the impact of agency decisions, if some regulatees do behave differently as a consequence. Thus, in such cases, as the example of the SEC illustrates, IRAs may confront a dilemma about choosing their best strategies: while some may be tempted to take some risks, others would prefer not to do so. It might be the case that using selective accountability in some environments may put effective regulation in danger, creating a risk for the achievement of agency goals. In those cases, risk-averse agencies will prefer nonselective voluntary accountability mechanisms to avoid nurturing situations that could block agency goals. Under these circumstances, revealing agency preferences more in detail while paying attention to the context provides a better grasp of how IRAs navigate such dilemmas to improve their institutional profile.

Our discussion is a first step towards a more systematic study of how IRAs strategically use accountability mechanisms. In this way, we suggest that for IRAs, the "shadow of hierarchy" 
effect works differently than the way it would for conventional public agencies. For independent agencies, it is not the executive that activates institutional controls, but rather a combination of powers, including the legislative (and this is only activated in exceptional cases). Thus, to make accountability credible, IRAs have to reveal their vulnerability to regulatees in their exchanges, making such practices more exposed, but in defining their accountability strategies, agencies tend to choose the level of risk they like to operate under.

Unlike the reputation framework, which characterizes many studies on accountability in public agencies, our proposal presents a roadmap to study agencies' voluntary accountably with a focus on the strategic considerations to advance their regulatory goals under uncertainty, taking into account the distribution of power among regulatees and their attitudes towards risk. Crucially, these practices cannot be simply framed as voluntary commitments of dutiful IRAs' bureaucrats to improve their reputation among stakeholders avoiding risky decisions. They may have a substantive policy content. Depending on the mandatory accountability requirements and the nature of regulatees' interactions, IRAs may actually feel constrained or compelled to rely on distinct accountability strategies and to promote their different goals more intensively. However, the consequences of their choices can be relevant for the achievement of agency regulatory goals. In that sense, understanding IRAs' voluntary accountability choices calls for an interpretative framework.

Finally, a focus on IRA accountability further speaks to studies that seek to understand the logic of decision-making in regulatory governance, including those across regulatory regimes, spaces and networks (Coen and Heritier 2005, Gonzalez 2017, Hancher and Moran 1989, Jordana and Sancho 2004,). Often, IRAs' accountability involves ex-post justifications of decisions that are taken after multiple interactions with stakeholders. This interactive component suggests that IRAs-despite their independence-are not completely isolated when they reach critical decisions governing the market. Very importantly, these agencies are embedded in complex networks of actors and institutions. A better understanding of these contextual dynamics calls for further research that systematically problematizes power asymmetries among regulatees as a conditioning factor for agencies' discretionary activities, such as the use of voluntary accountability.

\section{Bibliography}

Baldwin, R., Cave, M., \& Lodge, M. (2012). Understanding Regulation: Theory, Strategy, and Practice. OUP Oxford.

Baker, A. (2010). Restraining regulatory capture? Anglo-America, crisis politics and trajectories of change in global financial governance. International Affairs, 86(3), 647-663.

Biela, J. (2014). Accountability: On the Measurement of an Elusive Concept. Paper prepared for the 5th Biennial Conference of the ECPR Standing Group on Regulatory Governance, Barcelona, 25-27 June 2014.

Biela, J., \& Papadopoulos, Y. (2014). The empirical assessment of agency accountability: a regime approach and an application to the German Bundesnetzagentur. International Review of Administrative Sciences, 80(2), 362-381.

Black, J. (2008). Constructing and contesting legitimacy and accountability in polycentric regulatory regimes. Regulation \& Governance, 2(2), 137-164. 
Bovens, M. (2007). Analysing and Assessing Accountability: A Conceptual Framework. European Law Journal, 13(4), 447-468.

Bovens, M., R. Goodin and T. Schillemans (2014). Public Accountability. In M. Bovens, R. E. Goodin, and T. Schillemans (eds.) The Oxford Handbook of Public Accountability. Oxford: Oxford University Press.

Busuioc, M. (2013). European Agencies: Law and Practices of Accountability. Oxford: OUP.

Busuioc, E. M., \& Lodge, M. (2015). The Reputational Basis of Public Accountability. Governance, 29(2), 247-263.

Carpenter, D. P. \& Krause, G.A. (2015). Transactional Authority and Bureaucratic Politics, Journal of Public Administration Research and Theory, 25(1), 5-25.

Carpenter, D. P., \& Krause, G. A. (2012). Reputation and Public Administration. Public Administration Review, 72(1), 26-32.

Christensen, T., \& Lægreid, P. (Eds.) (2006). Autonomy and regulation: Coping with agencies in the modern state. Cheltenham: Edward Elgar Publishing.

Coen, D., \& Héritier, A. (2005). Refining Regulatory Regimen. Cheltenham: Edward Elgar Publishing. Dal Bó, E., (2006). Regulatory capture: a review. Oxford Review of Economic Policy, 22(2), 203-225.

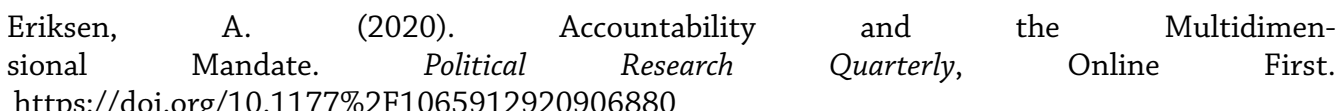
https://doi.org/10.1177\%2F1065912920906880

Fernández-i-Marín, X., Jordana, J., \& Bianculli, A. (2015). Varieties of accountability mechanisms in regulatory agencies. In A. Bianculli et al. (Eds.), Accountability and Regulatory Governance (pp. 2350). Palgrave Macmillan, London.

Gilardi, F. (2008). Delegation in the Regulatory State: Independent Regulatory Agencies in Western Europe. Cheltenham: Edward Elgar.

Gilardi, F., \& Magetti, M. (2011). The Independence of Regulatory Authorities. In D. Levi-Faur (Ed.), Handbook on the Politics of Regulation (Chapter 14). Northhampton, MA: Edward Elgar Publishing.

Grabosky, P. (1995a). Regulation by Reward: On the Use of Incentives as Regulatory Instruments. Law \& Policy, 17(3), 257-282.

Grabosky, P. N. (1995b). Using Non-Governmental Resources to Foster Regulatory Compliance. Governance, 8(4), 527-550.

Guidi, M. (2015), Modelling the Relationship Between Independence and Accountability of Regulatory Agencies. In Bianculli et al. (Eds), Accountability and Regulatory Governance (pp. 105-122). Basingstoke: Palgrave Macmillan.

Hancher, L., \& Moran, M. (1989). Organizing Regulatory Space. In L. Hancher \& M. Moran (Eds), Capitalism, Culture and Economic Regulation (pp. 271-299) Oxford: Clarendon Press.

Hanretty, C., \& Koop, C. (2012). Measuring the formal independence of regulatory agencies. Journal of European Public Policy, 19(2), 198-216.

Jordana, J and D. Sancho (2004), Regulatory designs, institutional constellations and the study of the regulatory state. In J. Jordana \& D. Levi-Faur (Eds.), The Politics of Regulation. Institutions and Regulatory Reforms for the Age of Governance, Edward Elgar, Cheltenham.

Jordana, J., A. C. Bianculli and X. Fernández-i-Marín (2015). When Accountability Meets Regulation. In A. C. Bianculli, et al. (Eds.) Accountability and Regulatory Governance (pp. 23-50). Basingstoke: Palgrave Macmillan. 
Jordana, J., Fernández-i-Marín, X. \& Bianculli, A.C. (2018). Agency proliferation and the globalization of the regulatory state: Introducing a data set on the institutional features of regulatory agencies. Regulation and Governance, 12(4), 524-540.

Keohane, R. O. (2006). Accountability in World Politics. Scandinavian Political Studies, 29(2), 75-87.

Koop, C. (2011). Explaining the Accountability of Independent Agencies: The Importance of Political Salience. Journal of Public Policy, 31(02), 209-234.

Koop, C. (2014). Theorizing and Explaining Voluntary Accountability. Public Administration, 92(3), $565-581$.

Koop, C., \& Hanretty, C. (2018). Political independence, accountability, and the quality of regulatory decision-making. Comparative Political Studies, 51(1), 38-75.

Magetti, M. (2010). Legitimacy and Accountability of Independent Regulatory Agencies: A Critical Review. Living Reviews in Democracy. 2, 1-9.

May, P. J. (2007). Regulatory regimes and accountability. Regulation \& Governance, 1(1), 8-26.

Mishkin, F. (2004). Can Central Bank Transparency Go Too Far, NBER Working Paper Series. Retrieved from: https://www.rba.gov.au/publications/confs/2004/pdf/mishkin.pdf

Olson, M. (1965), The Logic of Collective Action. Public Goods and the Theory of Goods. Cambridge MA: Harvard University Press.

Przeworski, A., Stokes, S. C., \& Manin, B. (Eds.). (1999). Democracy, accountability, and representation (Vol. 2). Cambridge University Press.

Puppis, M., Maggetti, M., Gilardi, F., Biela, J., \& Papadopoulos, Y. (2014). The Political Communication of Independent Regulatory Agencies. Swiss Political Science Review, 20(3), 388-412.

Schillemans, T., (2008). Accountability in the shadow of hierarchy: The horizontal accountability of agencies. Public Organization Review, 8(2), 175-194.

Schillemans, T. (2011). Does Horizontal Accountability Work?: Evaluating Potential Remedies for the Accountability Deficit of Agencies. Administration \& Society, 43(4), 387-416.

Schillemans, T., \& Busuioc, M. (2014). Predicting Public Sector Accountability: From Agency Drift to Forum Drift. Journal of Public Administration Research and Theory, 25(1), 191-215.

Scott, C. (2000). Accountability in the Regulatory State. Journal of Law and Society, 27(1), 38-60.

Vershuere, B., K. Verhoest, F. Meyers and B.G. Peters. (2006). Accountability and Accountability Arrangements in Public Agencies. In T. Christensen \& P. Laegreid (eds.) Autonomy and Regulation. Northhampton, MA: Edward Elgar.

Verhoest, K., Peters, B. G., Bouckaert, G., \& Verschuere, B. (2004). The study of organisational autonomy: a conceptual review. Public Administration and Development, 24(2), 101-118.

Verhoest, K., Roness, P., Verschuere, B., Rubecksen, K., \& MacCarthaigh, M. (2010). Autonomy and Control of State Agencies: Comparing States and Agencies. Palgrave Macmillan UK.

Vibert, F. (2007). The rise of the unelected: democracy and the new separation of powers. Cambridge University Press.

Wilson, J. Q. (1980). The Politics of regulation. New York, NY: Basic Books.

Wood, M. (2015). Beyond accountability: Political legitimacy and delegated water governance in Australia. Public Administration, 93(4), 1012-1030. 